\title{
Analysis on passive residual heat removal system with heat pipes for longterm decay heat removal of small lead-based reactor
}

\author{
Chongju Hu, ${ }^{\mathrm{a}, \mathrm{b}, \mathrm{c}}$, Wangli Huang ${ }^{\mathrm{a}, *}$, Zhizhong Jiang ${ }^{\mathrm{a}}$, Qunying Huang ${ }^{\mathrm{a}}$, Yunqing Bai ${ }^{\mathrm{a}}$, Xiaoyu Cheng ${ }^{\mathrm{a}}$, Dali Yu $^{\mathrm{a}}$ \\ ${ }^{a}$ Key Laboratory of Neutronics and Radiation Safety, Institute of Nuclear Energy Safety Technology, HFIPS,Chinese Academy of Sciences, Hefei, Anhui \\ 230031, China \\ ${ }^{\mathrm{b}}$ University of Science and Technology of China, Hefei, Anhui 230027, China \\ c Suzhou University, Suzhou, Anhui 234000, China
}

\begin{abstract}
A lead-based reactor with employing heat pipes as passive residual heat removal system (PRHRS) for longterm decay heat removal was designed. Three-dimensional computational fluid dynamics (CFD) software FLUENT was adopted to simulate the thermal-hydraulic characteristics of the PRHRS under Station-Black-Out (SBO) accident condition. The results showed that heat in the core could be removed smoothly by the PRHRS, and the core temperature difference is less than $20 \mathrm{~K}$.
\end{abstract}

\section{Introduction}

Razzaque proposed to adopt heat pipes as the PRHRS for liquid metal cooled reactors and evaluated the impact of different cooling environment on the heat pipe system. However, his research were only qualitative evaluations, no quantitative analysis was investigated for a specific reactor[1]. Wang et al. simulated the start-up process of sodium heat pipes, which were used as the PRHRS of the reactor[2]. The results showed that the heat pipes have good heat transfer performance. Mochizuki et al. employed the loop heat pipe as the PRHRS and implemented the theoretical calculation to analyze its feasibility and characteristics[3]. The results showed that heat pipes are able to reduce the reactor temperature from the operation temperature $282^{\circ} \mathrm{C}$ to below $250{ }^{\circ} \mathrm{C}$ within $7 \mathrm{~h}$. Qin et al. proposed a method to directly insert the heat pipes into the containment for long-term residual heat removal and studied the influence of different operation conditions on the process parameters of the system by experiments[4]. The results showed the heat transfer efficiency was significantly improved, and the heat pipes could effectively reduce the heat accumulation in the containment and delay the temperature increase of the water coolant in the containment.

The above researches mainly focus on whether the heat pipe can effectively remove the residual heat. However, the temperature distribution in the whole reactor has not been well ${ }^{1}$ studied. In this paper, a small leadbased reactor with heat pipes as the PRHRS has been designed. The thermal resistance model was applied to the heat pipe simulation to realize the joint thermal-hydraulic performance simulation of the reactor and the heat pipes. The temperature characteristics of the heat pipe reactor were studied by using FLUENT. The present work provides knowledge basis for the design of the lead-based reactor with a heat pipes based PRHRS.

\section{Reactor design description}

A heat pipe nuclear reactor employing lead-bismuth eutectic (LBE) as a coolant is designed as shown in Figure.1 and the main parameters are listed in Table 1. The primary cooling system is divided into a cold pool and a hot pool by a heat shield. LBE in the cold pool is driven by the main pump, flows into the core through the heat pool, the reflector, the heat pipe and two primary heat exchangers (PHXS) for heat transfer, and finally back into the cold pool. The residual heat is removed by the heat pipes through thermal radiation while the reactor is shut down. The thermal power of the reactor is $6 \mathrm{MW}$. The inlet and outlet temperatures of the reactor core are $683 \mathrm{~K}$ and $733 \mathrm{~K}$, respectively. The mass flow rate of LBE is $827 \mathrm{~kg} / \mathrm{s}$ 


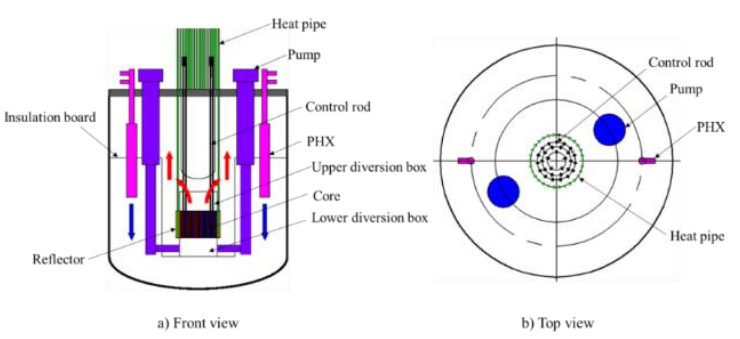

Figure.1 The LBE reactor design with a heat pipes based PRHRS

\begin{tabular}{ll}
\multicolumn{2}{l}{ Table 1 Main parameters for the LBE reactor } \\
\hline Parameter & Value \\
\hline Thermal power (MW) & 6 \\
Fission fuel & $\mathrm{UO} 2$ \\
Cladding & $\mathrm{T} 91$ \\
Primary coolant & $\mathrm{LBE}$ \\
Reflector & $\mathrm{Be}$ \\
Maximum clad temp. $(\mathrm{K})$ & 1025 \\
Coolant mass flow rate $(\mathrm{kg} / \mathrm{s})$ & 827 \\
Core inlet/outlet temp. $(\mathrm{K})$ & $683 / 733$ \\
Core height $(\mathrm{m})$ & 0.8 \\
Core diameter (m) & 1.1 \\
Number of PHXs & 2 \\
Number of main pumps & 2 \\
Number of heat pipes & 30 \\
Main vessel height (m) & 5.6 \\
Main vessel diameter (m) & 4.9 \\
\hline
\end{tabular}

The heat pipes are introduced and placed uniformly in the reflector of the reactor in order to remove the decay heat as the main equipment for the PRHRS of the reactor. The specific structural parameters are listed in Table 2.

Table 2 Main parameters of the heat pipes

\begin{tabular}{ll}
\hline Parameter & Value \\
\hline Working fluid & $\mathrm{Hg}$ \\
Material of heat pipes and wicks & $316 \mathrm{~L}$ \\
Outer diameter of pipe (mm) & 40 \\
Pipe wall thickness (mm) & 1 \\
Annular thickness (mm) & 0.5 \\
Wick thickness (mm) & 0.2 \\
Total length (m) & 5.46 \\
Length of condensation section $(\mathrm{m})$ & 1.12 \\
\hline
\end{tabular}

\section{Calculation model description and validation}

\subsection{The geometry model of the LBE reactor}

Due to the complex structure of the reactor and the large difference in internal structure size, the difficulty of meshing is greatly increased. For this reason, the momentum is directly loaded on the core to simulate the primary pumps' operation. A $1 / 2$ 3D CFD symmetry model was built in this paper for calculations as shown in Figure.2.

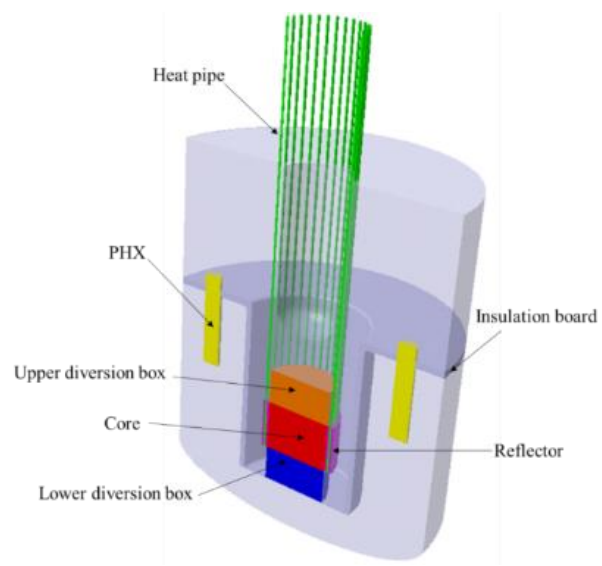

Figure.2. Geometry model of the PRHRS with heat pipes for the $\mathrm{LBE}$ reactor

\subsection{The PHX model}

The PHX is a heat sink to the core and simplified as a porous cylinder. The heat dissipation power of a single PHX is $3 \mathrm{MW}$. The inlet and outlet temperatures of the PHX are $683 \mathrm{~K}$ and $733 \mathrm{~K}$, respectively. A liner dependency of the heat flux based on the fixed inlet and outlet LBE temperatures of the PHXS is assumed, which can be used to calculate the heat exchange between the primary cooling system and the secondary cooling system. Then, the volumetric energy source term of the PHXS can be expressed as[5]

$$
\mathrm{Q}=-\frac{\mathrm{T}-683}{25} \times 3 \mathrm{MW} / \mathrm{V}_{\mathrm{PHX}}
$$

where $\mathrm{T}$ represents the temperature of the heat exchanger cell grid $[\mathrm{K}], \mathrm{V}_{P H X}$ is the volume of single $\mathrm{PHX}\left[\mathrm{m}^{3}\right]$.

\subsection{The reactor core model}

The reactor core is considered as a heat source with uniform distribution and the volumetric heat release rate is $6 \mathrm{MW} / \mathrm{V}_{\text {core, }}$ where the $\mathrm{V}_{\text {core }}$ refers to the core volume. Additional momentum source term composed of the viscous loss and the inertia loss was added into the momentum equation, and the momentum source term can be calculated through the thermal-hydraulic analysis of the reactor under different Reynolds numbers.

\subsection{The heat pipe model}

Since the heat pipe involves complicated multi-phase flow and porous medium flow, and the diameter of the wire meshes are micro-scale which is difficult to perform mesh division. The heat pipe thermal resistance model consists of both series and parallel connections of the thermal resistances. The diagram of the model is shown in Figure.3. $\mathrm{R}_{1}, \mathrm{R}_{2}$, and $\mathrm{R}_{3}$ represent the radial thermal resistance of the evaporation section wall, the radial thermal resistance of the wick in the evaporation section, and the evaporation heat resistance, respectively. $\mathrm{R}_{4}$ represents the thermal resistance of the axial flow of steam. $R_{5}, R_{6}$, and $R_{7}$ represent the condensation heat resistance, the radial thermal resistance of the wick in the condensation section, 
and the radial thermal resistance of the condensation section wall, respectively. $\mathrm{R}_{8}$ and $\mathrm{R}_{9}$ represent the axial thermal resistance of the tube wall and the axial thermal resistance of the wick, respectively.

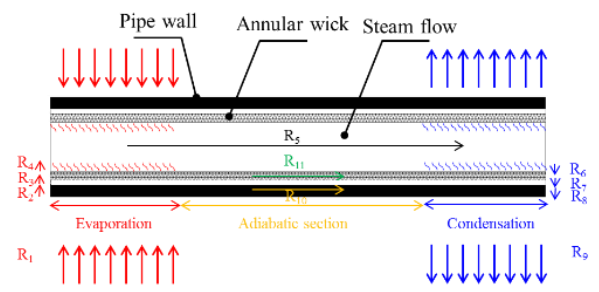

a) Structure diagram of the thermal resistance

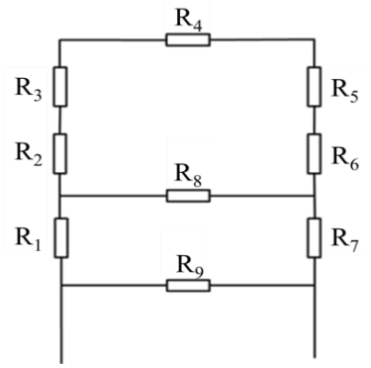

b) Schematic diagram of the thermal resistance

Figure.3 Thermal resistance model of a heat pipe

\subsection{Boundary conditions}

The k-epsilon RNG turbulence model is adopted to perform the simulations[6]. Radiation boundary condition is used in the condensation section of heat pipes and adiabatic boundary condition is used in the other contact surfaces with the environment in the model, such as the outer wall and the top of the pressure vessel. All the calculations are based on the conservation of energy, mass, and momentum. The system is considered as steady state. Moreover, the pressure-based steady solver is adopted.

\subsection{Grid sensitivity analysis}

In order to get accurate results, it is necessary to ensure that the results don't change with the number of meshes. In this paper, Three different grid numbers is adopted, and the grid number is increased by twice each time. The different average temperature output of core outlet for different mesh value with the same boundary conditions are extracted and plotted in the Figure.4. It indicates that the results of 1 million mesh and 2 million mesh are basically consistent, while the 0.5 million mesh is difference with the two other. Therefore, considering the computational time and accuracy, the 1.178425 million grid was selected.

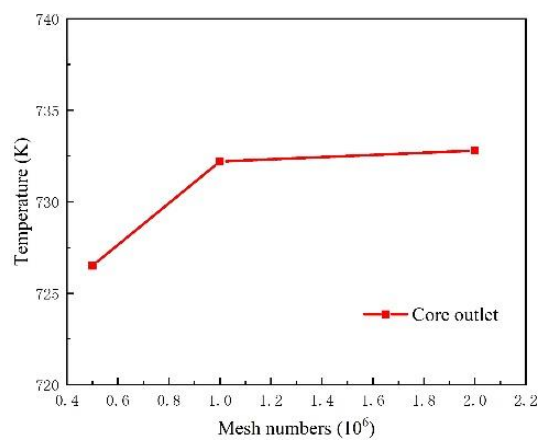

Figure. 4 The average core outlet Simulation temperature for different mesh Numbers

\subsection{Thermal validation of the LBE reactor numerical model}

A set of thermal-hydraulic calculation formula for the LBE reactor are prepared, which are mainly based on mature thermal theory for the reactor [7]. The reactor CLEAR-I is calculated by this calculation formula, and the results are compared with the design parameters published in the literature of the reactor[8], the results are listed in Table 3. Finally, results calculated with the simulation were compared with the design values as mentioned in the Table 3. It can be seen that the calculated results of the theoretical calculation formula are in good agreement with the design parameters of CLEAR-I.

Table 3 Comparison of design parameters and theoretical calculation results

\begin{tabular}{lccc}
\hline Parameter & $\begin{array}{c}\text { CLEAR-I } \\
\text { design }\end{array}$ & $\begin{array}{c}\text { Theoretical } \\
\text { calculation }\end{array}$ & $\begin{array}{c}\text { Relative } \\
\text { error }\end{array}$ \\
\hline $\begin{array}{l}\text { Average core inlet } \\
\text { temperature }\end{array}$ & $573 \mathrm{~K}$ & $573 \mathrm{~K}$ & 0 \\
$\begin{array}{l}\text { Average core } \\
\text { outlet temperature }\end{array}$ & $\begin{array}{l}658 \mathrm{~K} \\
\begin{array}{l}811.7 \\
\mathrm{~kg} / \mathrm{s}\end{array}\end{array}$ & $658 \mathrm{~K}$ & 0 \\
Coolant mass flow & $81.36 \mathrm{~kg} / \mathrm{s}$ & $0.04 \%$ \\
\hline
\end{tabular}

Table 4 shows thermal-hydraulic parameters comparison of calculation results and CFD simulation results. The theoretical and CFD simulation results are in good agreement with each other, and the maximum error is no more than $0.5 \%$.

Table 4 Calculation and simulation results

\begin{tabular}{lccc}
\hline Parameter & $\begin{array}{c}\text { Theoretical } \\
\text { calculation }\end{array}$ & $\begin{array}{c}\text { CFD } \\
\text { simulation }\end{array}$ & $\begin{array}{c}\text { Relative } \\
\text { error }\end{array}$ \\
\hline $\begin{array}{l}\text { Average core inlet } \\
\text { temperature }\end{array}$ & $683 \mathrm{~K}$ & $681.5 \mathrm{~K}$ & $0.2 \%$ \\
$\begin{array}{l}\text { Average core } \\
\text { outlet temperature }\end{array}$ & $733 \mathrm{~K}$ & $732.2 \mathrm{~K}$ & $0.1 \%$ \\
Coolant mass flow & $827.0 \mathrm{~kg} / \mathrm{s}$ & $830.8 \mathrm{~kg} / \mathrm{s}$ & $0.5 \%$ \\
\hline
\end{tabular}

\section{Results and discussions}

Figure.5 shows the flow field distribution at the symmetrical plane during the SBO accident. The flow direction of the coolant in the core and heat exchanger 
shows the existence of a few natural cycles in the reactor vessel and the flow direction is consistent with the normal operation. There are obvious swirl flows occurred in the flow field near to the heat pipe. The existence of the heat pipe leads to the local temperature imbalance and forms the local natural circulation of fluid, which promote the heat release from the reactor core.

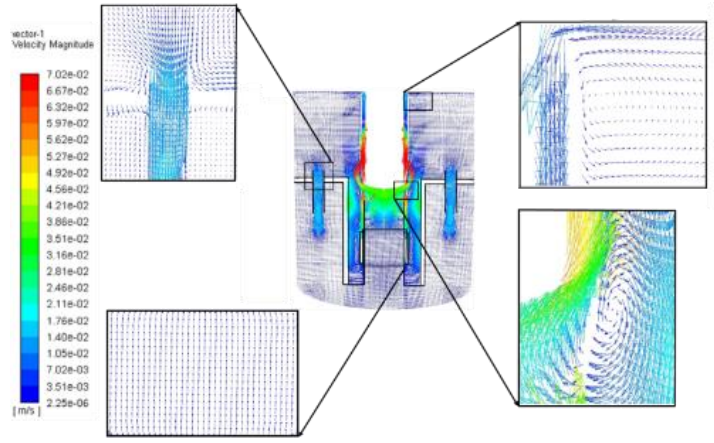

Figure.5 Velocity distribution of reactor symmetry plane during SBO accident

Figure. 6 shows the temperature distribution of the core. The temperature of core is high in the middle and low on both sides in the axial direction, which is very different from the results of RAVCS RHRS[7]. However, the maximum core temperature difference is less than $20 \mathrm{~K}$ and there is no obvious change in temperature of core in the radial direction, it indicates that although the convection caused by natural circulation is very small, it plays an important role in limiting the core temperature difference.

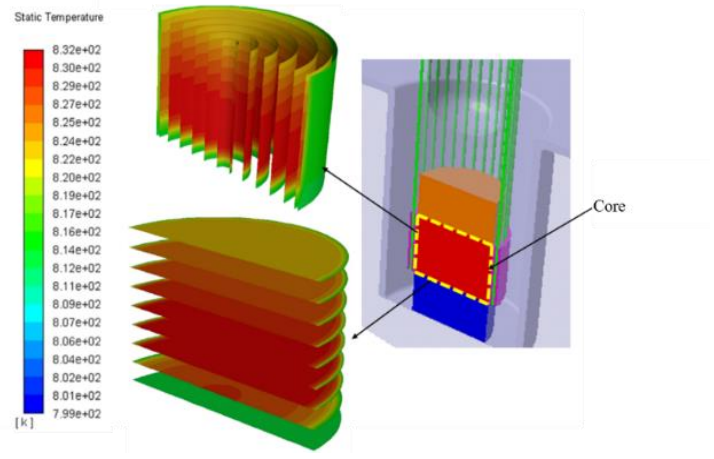

Figure.6 Temperature distribution of reactor core during SBO accident

Figure.7 shows the temperature contour of the reflector and heat pipes, which are rotated clockwise by $90^{\circ}$ for better visualization of the temperature. It is clear that the average temperature difference between the evaporation section and the condensation section of the heat pipe is less than $10 \mathrm{~K}$, which further proves the good heat conduction characteristics of the heat pipe. From the axial direction of the heat pipe, The maximum temperature difference of the mercury vapor in the heat pipe is no more than $2 \mathrm{~K}$, whereas there is a large temperature gradient in the wall thickness of the heat pipe and the wick in the radial direction of the heat pipe. The maximum temperature difference can be up to $8 \mathrm{~K}$ in the evaporation section and the condensation section. Hence, it can be concluded that the thermal resistance of the heat pipes mainly occurs in the radial direction and this characteristic of the heat pipes can be used to realize long-distance heat transfer with a low temperature drop.

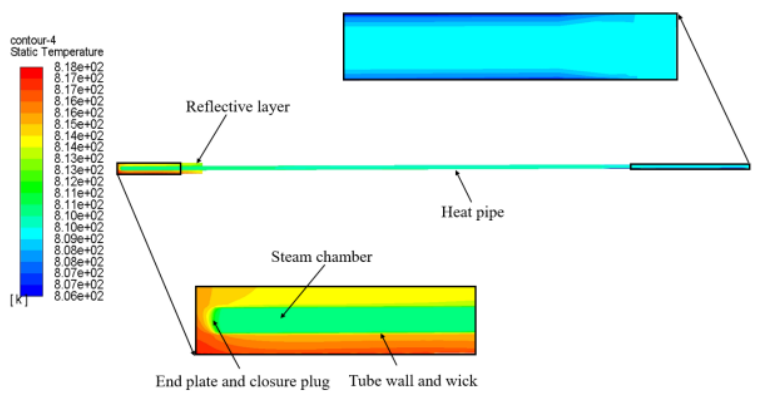

Figure.7 Temperature distribution of a heat pipe and the reflector during normal operation

\section{Acknowledgments}

Financial support from the CASHIPS Director's Fund(No.YZJJ2021QN36 ) is acknowledged.

\section{Conclusion}

A LBE reactor with a heat pipes based PRHRS was designed, and a three-dimensional numerical simulation model of the reactor was established with reasonable simplification. The distribution of temperature and velocity fields in the reactor with a heat pipes based PRHRS under accident conditions were analyzed. The results showed the nuclear reactor can ensure the safety of the core on the SBO accident condition. When the reactor is during $\mathrm{SBO}$ accident, there is no large temperature difference in the reactor core due to convection, and the maximum difference is less than $20 \mathrm{~K}$.

\section{References}

1. Razzaque M M., 1990. On application of heat pipes for passive shutdown heat removal in advanced liquid metal and gas-cooled reactor designs. Annals of Nuclear Energy. 17(3), 139-142.

2. Wang C L, Zhang D L, Qiu S Z, et al., 2013. Study on the characteristics of the sodium heat pipe in passive residual heat removal system of molten salt reactor. Nuclear Engineering and Design. 265, 691-700.

3. Mochizuki M, Singh R, Nguyen T, et al., 2014. Heat pipe based passive emergency core cooling system for safe shutdown of nuclear power reactor. Applied Thermal Engineering. 73(1), 699-706.

4. Qin H Q, Lu D G, Wang S F, et al., 2017. The application of heat pipe discharge containment heat experimental study: new type of passive containment heat removal system concept design. Proceedings of the 25th International Conference on Nuclear Engineering. Shanghai, China: ASME.7.

5. Zhao P C, Li S Z, Chen Z, et al., 2015. Natural circulation characteristics analysis of a small modular natural circulation lead-bismuth eutectic cooled fast 
reactor. Progress in Nuclear Energy. 83, 220-228.

6. Vanderhaegen M, Vierendeels J, Arien B, et al., 2011. CFD analysis of the MYRRHA primary cooling system. Nuclear Engineering and Design. 241(3), 775-784.

7. Wang X J, Jin M, Wu G W, et al., 2016. Natural circulation characteristics of lead-based reactor under longterm decay heat removal. Progress in Nuclear Energy. 90, 11-18.

8. James J. Duderstadt, Louis J. Hamilton., 1976.

Nuclear Reactor Analysis. John Wiley and Sons, Inc; New York, pp. 467-536. 